\title{
Cytological Observations on Some West Himalayan Orchids Tribe: Epidendreae II (Subtribes: Liparidinae, Oberoniinae, Dendrobiinae)
}

\author{
P. N. Mehra and S. K. Kashyap \\ Botany Department, Panjab University, Chandigarh, India
}

Received October 20, 1982

This paper presents cytological information on 24 West Himalayan species belonging to the subtribes Liparidinae, Oberoniinae and Dendrobiinae. Members of the subtribe Dendrobiinae are of immense horticultural value. Dressler and Dodson (1960) placed Liparis and Oberonia under the subtribe Liparidinae. On the other hand Mehra and Kaushik (unpublished) on the basis of a comparative study of the anatomical features of the species belonging to the two genera suggest the erection of a separate subtribe, Oberoniinae, for Oberonia. Cytologically, this ranking seems to be correct from what follows.

\section{Material and methods}

Material and methods of investigation, magnification of the photomicrogaphs which is uniform in all cases etc, are the same as in our previous paper of the series (cf. Mehra and Kashyap 1983.) Voucher specimens have been deposited in the Herbarium of the Department of Botany, Panjab University, Chandigarh.

Table 1 summarises the results of the present investigation. A few notes are presented below for individual taxon.

\section{Results and discussion}

Subtribe: Liparidinae Bentham

Thirteen species included in 3 genera have been investigated presently.

\section{Liparis Rich.}

This great cosmopolitan and complex genus comprises 250 terrestrial and epiphytic species which are distributed in tropical and temperate countries, except New Zealand (Airy Shaw 1973). Only 9 species occur in the Western Himalayas (Duthie 1906) of which 5 have been studied. Pollen grains in all of them form soft pollinia.

L. cordifolia Hook. f. is a terrestrial species which grows in shady situations at about $2000 \mathrm{~m}$. Flowering period is August-September.

Meiotic studies revealed 10 bivalents at MI (Fig. 1) of which five were larger than the rest. Meiotic course was normal. The species is worked out for the first time.

L. deflexa Hook. f. is a low level terrestrial species which grows under the shade 


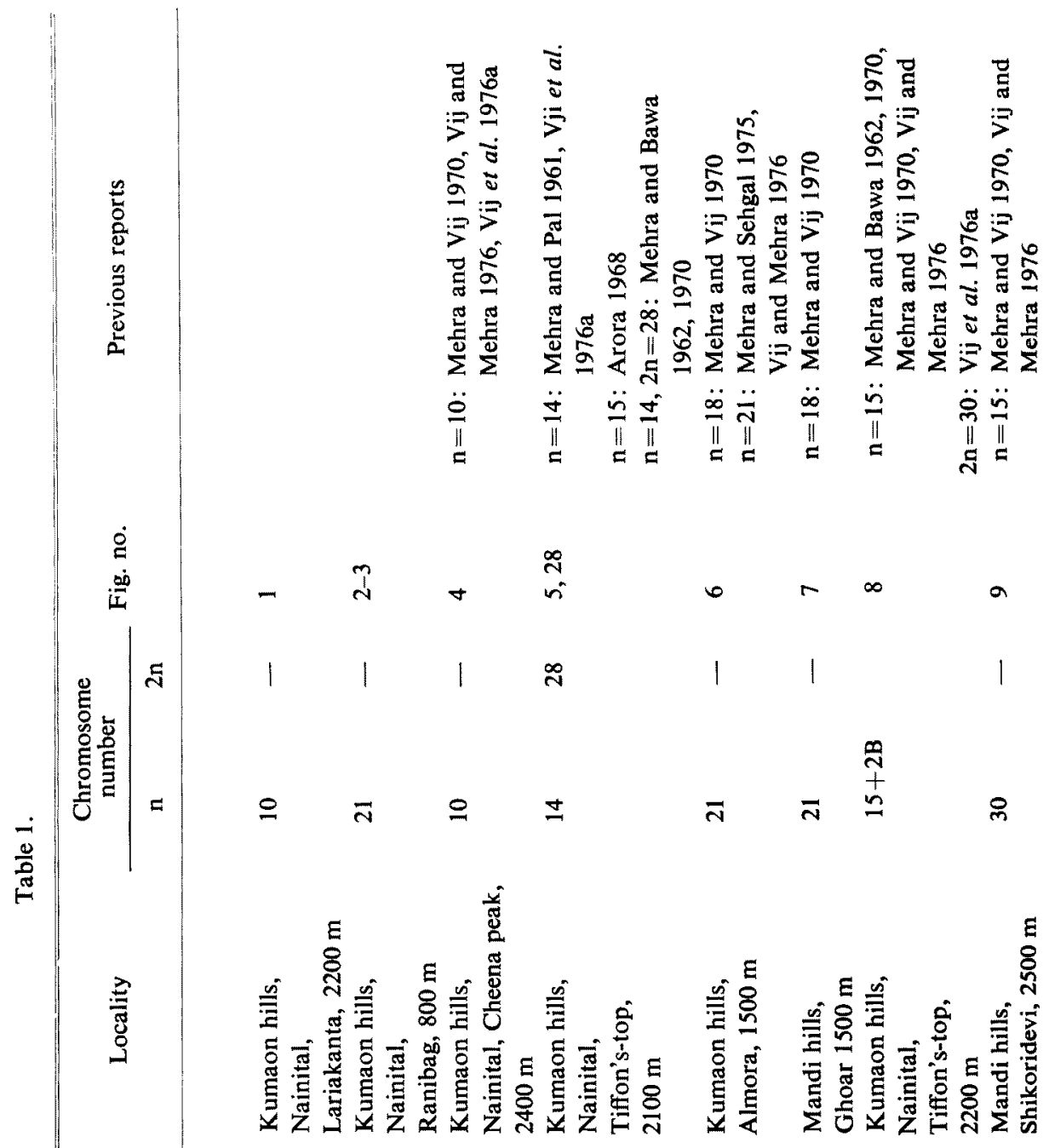




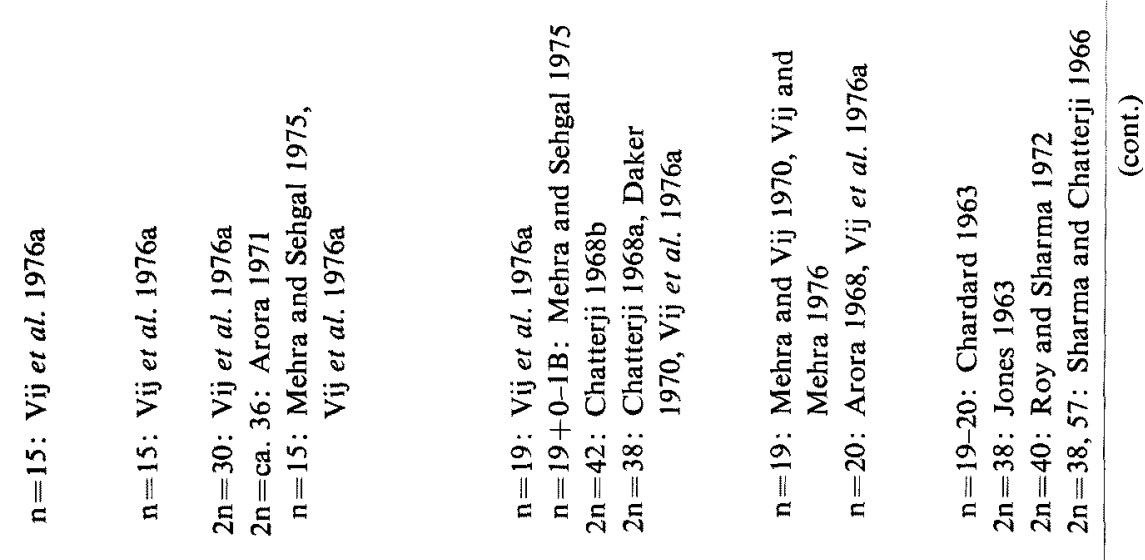

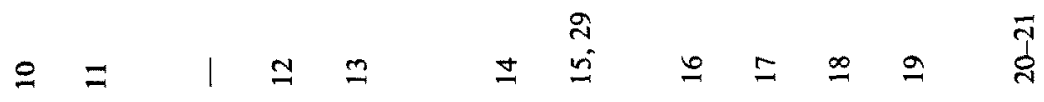

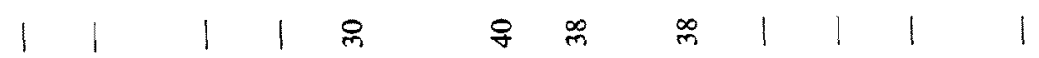

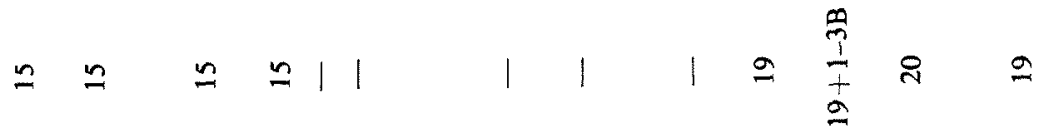

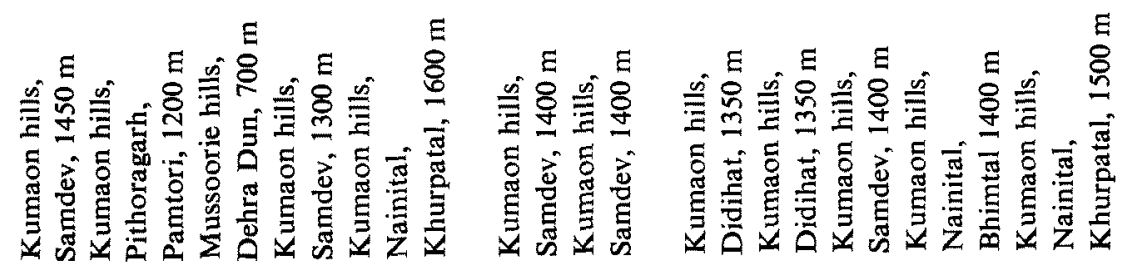

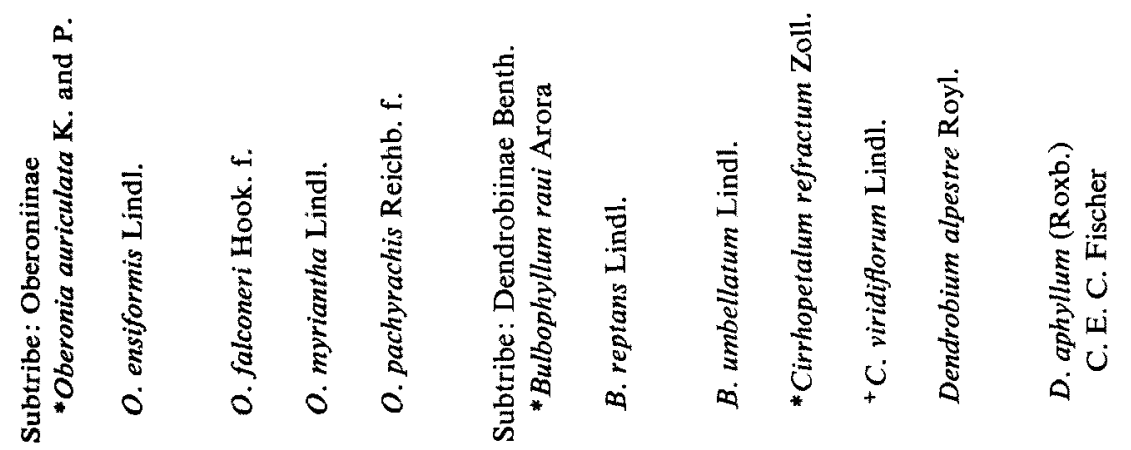




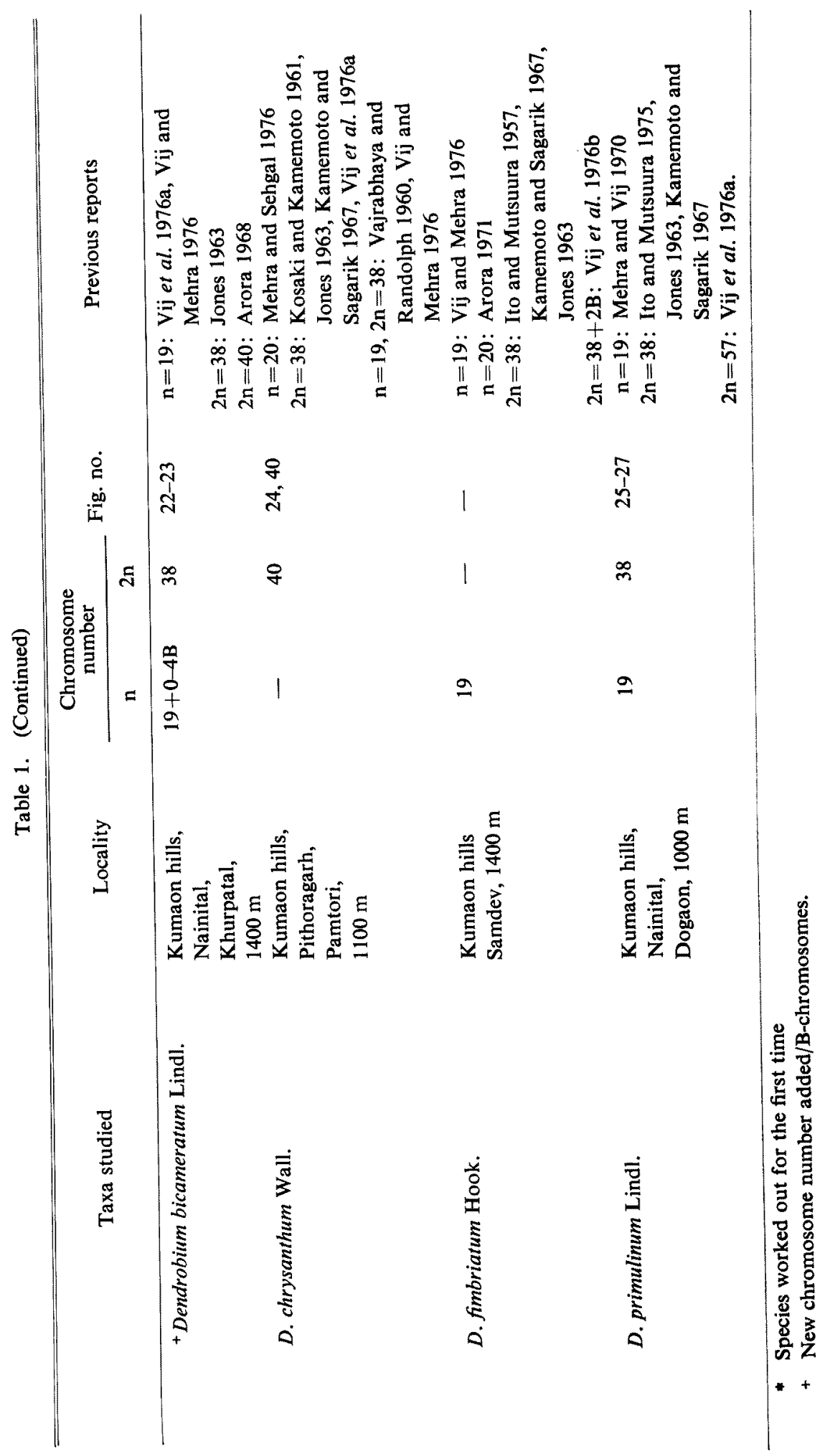


of trees in the Kumaon hills at an altitude of about $900 \mathrm{~m}$. Its flowering period is July-August.

Meiotic studies revealed $n=21$ at diakinesis (Figs. 2, 3). Bivalents were both ring- and rod-shaped. This species is also investigated for the first time.

L. glossula Rich. is also a terrestrial species which grows in open grassy slopes or on humus-rich black soil under trees. It is common in Kumaon hills at about $2400 \mathrm{~m}$. Flowering period is June-July.

Ten bivalents of almost the same size were noticed at M-I (Fig. 4). This count confirms the previous reports by Mehra and Vij (1970) and Vij et al. (1976a).

L. rostrata Reich. A widely distributed species of the Western Himalayas which grows commonly in moist, shady situations between $2100-2300 \mathrm{~m}$. Its flowering period is July-August.

Meiotic studies showed 14 bivalents at diakinesis, of which five bivalents were comparatively larger than the rest. Smaller bivalents showed precocious disjunction. An occasional non-conjugating bivalent was noticed at M-I. Further meiotic course was normal.

The gametic number was further confirmed by somatic counts from root tip squashes which revealed $2 n=28$ chromosomes (Fig. 5). The chromosomes measured from $2.38-0.52 \mu$. Total chromosome length is $35.76 \mu$. The karyotype formula is $18 \mathrm{~m}+8 \mathrm{sm}+2 \mathrm{st}$ (Fig. 28).

The present report of $n=14,2 n=28$ confirms the earlier reports (Mehra and Pal 1961, Vij et al. 1976a, Mehra and Bawa 1970) for the species. However Arora (1968) reported $n=15$.

L. paradoxa Reichb. $\mathrm{f}$. is a widely distributed terrestrial species of the Western Himalayas which grows in open grassy slopes at an altitude of about $1600 \mathrm{~m}$. Several morphotypes are known which differ in plant size, flower colour and leaf shape. Flowering period is June-July.

Meiotic studies, however, uniformly revealed $n=21$ at M-I in all the morphotypes (Fig. 6). Some smaller bivalents showed precocious disjunction. Non-congressing chromosomes were observed in many cells. Further meiotic course was normal. The present count is in line with the report by Mehra and Sehgal (1975) and Vij and Mehra (1976).

The present investigation on 5 species of the genus showed variable numbers $\mathrm{n}=10,14,21$. All of them are terrestrial. The chromosomes are of medium size. The genus is polymorphic with considerable variation in the chromosome number $\mathrm{n}=10,14,15,16,18,19,20$ and 21 (cf. Tanaka and Kamemoto 1972, 1974) and size, and needs a thorough taxonomic revision. It may need splitting of the genus into more natural groups.

Malaxis Soland ex Sw.

The genus is cosmopolitan (except New Zealand) comprising 300 species (Airy Shaw 1973). Seidenfaden (1975) has merged Liparis and Malaxis under Microstylis.

M. acuminata Don. (= Microstylis wallichii Lindl.) is a terrestrial species widely distributed in the Western Himalayas growing in thick forests on humus-rich soil 

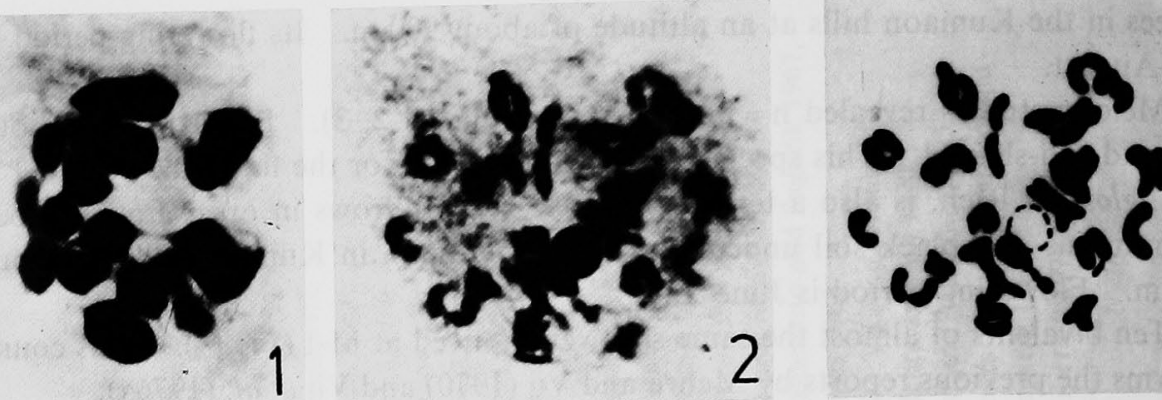

3
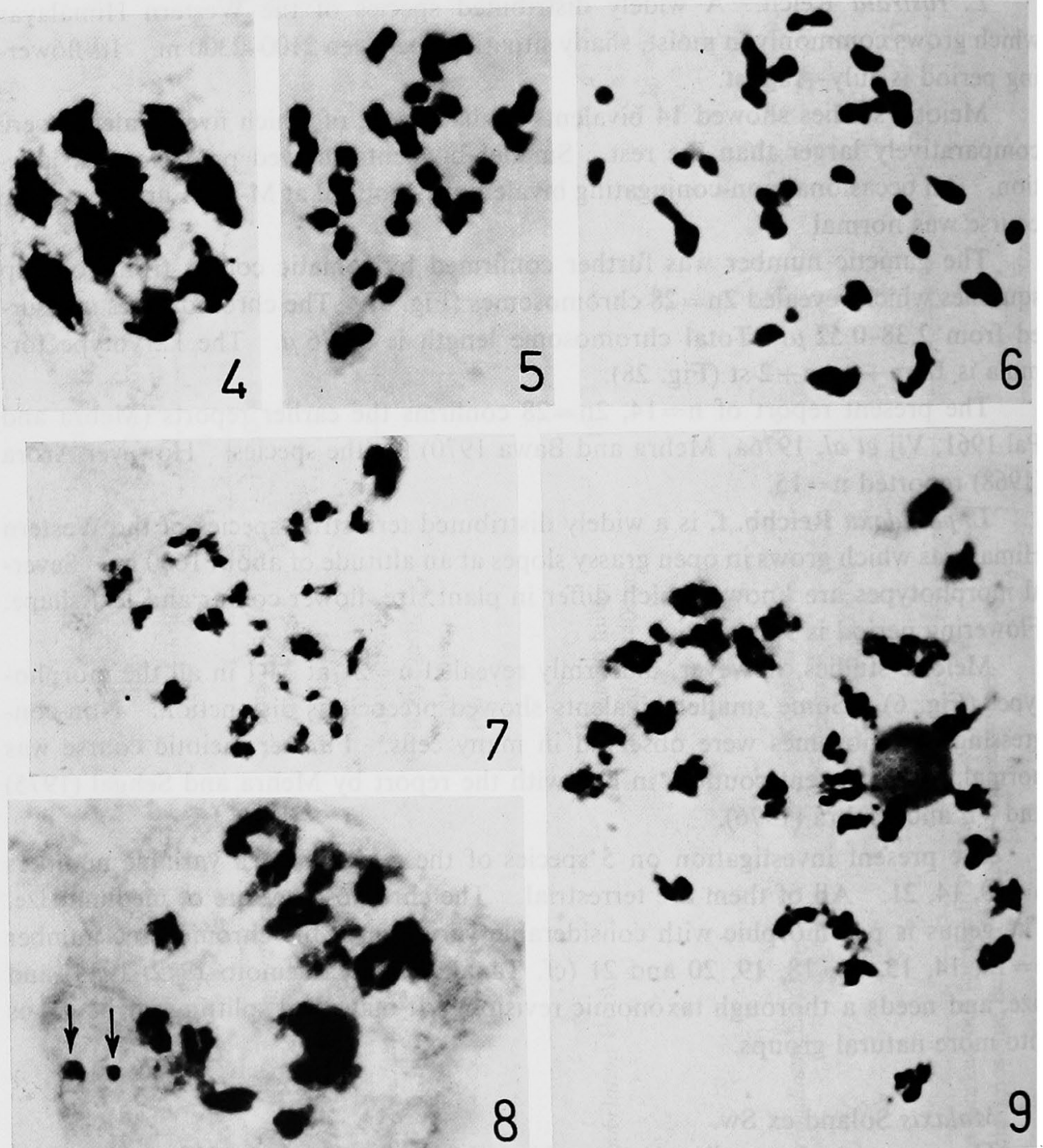

Figs. 1-9. Liparis cordifolia. 1, PMC with $\mathrm{n}=10$ at M-I. L. deflexa: 2, PMC with $\mathrm{n}=21$ at diakinesis. 3, explanatory diagram of figure 2. L. glossula: 4 , ten bivalents at M-I. L. rostrata: 5 , somatic cell with $2 \mathrm{n}=28$ at metaphase. L. paradoxa: $6, \mathrm{PMC}$ with $\mathrm{n}=21$ at $\mathrm{M}-\mathrm{I}$. Note precocious disjunction of some bivalents. Malaxis acuminata: $7, \mathrm{PMC}$ with $\mathrm{n}=\mathbf{2 1}$ at diakinesis. $M$. cylindrostachya: 8 , PMC with $\mathrm{n}=15+2 \mathrm{~B}$ 's at diakinesis (B's at arrow). M. muscifera: 9, PMC with $\mathrm{n}=30$ at diakinesis. 
at $1500-2000 \mathrm{~m}$. Its flowering period is from May-June.

Twenty one rather small bivalents were counted at diakinesis many of which showed precocious disjunction (Fig. 7). Meiotic course was normal. Pollen grains form soft pollinia.

$M$. cylindrostachya (Lindl.) $O$. Ktze. is also a widely distributed terrestrial species which grows under the shade of trees or in open places at $2100-2300 \mathrm{~m}$. Its flowering period is July-August.

Fifteen ring- and rod-shaped bivalents were clearly counted at diakinesis along with two small B-chromosomes in some cells (Fig. 8). Two bivalents were usually associated with the nucleolus. Pollen grains form soft pollinia one end of which is hyaline.

The present count $\mathrm{n}=15$ is in conformity with the earlier reports of Mehra and Bawa (1970) and Vij and Mehra (1976). The presence of B-chromosomes is recorded for the first time.

M. muscifera (Lindl.) O. Ktze. grows in the open grasslands or in forests from Kashmir to Kumaon hills at an altitude of $2400-2800 \mathrm{~m}$. Its flowering period is in July-August.

Thirty ring- and rod-shaped bivalents along with a nucleolus were seen at diakinesis (Fig. 9). Meiotic course was normal.

The only previous report for this species is $n=15$ (Mehra and Vij 1970, Vij and Mehra 1976) from the Eastern Himalayas. The present taxon thus is tetraploid, while that from the Eastern Himalayas is diploid.

Discordant chromosome numbers for the different species of the genus Malaxis are known i.e. $\mathrm{n}=15,18,19,20$ and 21 (cf. Tanaka and Kamenoto 1972, 1974). A further taxonomic revision of the genus is called for.

Subtribe: Oberoniinae

This subtribe which includes the genus Oberonia only has been segregated from Liparidinae (sensu stricto) on the basis of habit and anatomical characters by Mehra and Kaushik (unpublished data).

Oberonia Lindl.

A large genus covering nearly 330 palaeotropical, eptiphytic species (Airy Shaw 1973). Pollen grains in all the presently studied taxa possess small soft globular pollinia. Five species occurring in the Western Himalayas have been investigated which uniformly showed 15 chromosomes as the haploid number.

$O$. auriculata $\mathrm{K}$. and $\mathrm{P}$. is distributed in the Kumaon hills as an epiphyte in moist situations at an elevation of $1400 \mathrm{~m}$. Its flowering period is July-August.

Three of the 15 bivalents are significantly smaller in size (Fig. 10). Dyads, triads and tetrads have been noticed at the completion of meiosis. The species is newly investigated.

O. ensiformis Lindl. is an epiphyte in thick oak forests of Kumaon hills at $1100 \mathrm{~m}$ elevation. Flowering period is September-October.

At diakinesis 15 bivalents were counted (Fig. 11) which confirms the only earlier report of $n=15$ by Vij et al. (1976a).

o. falconeri Hook. f. is a common epiphyte on trunks of mango trees in Doon 

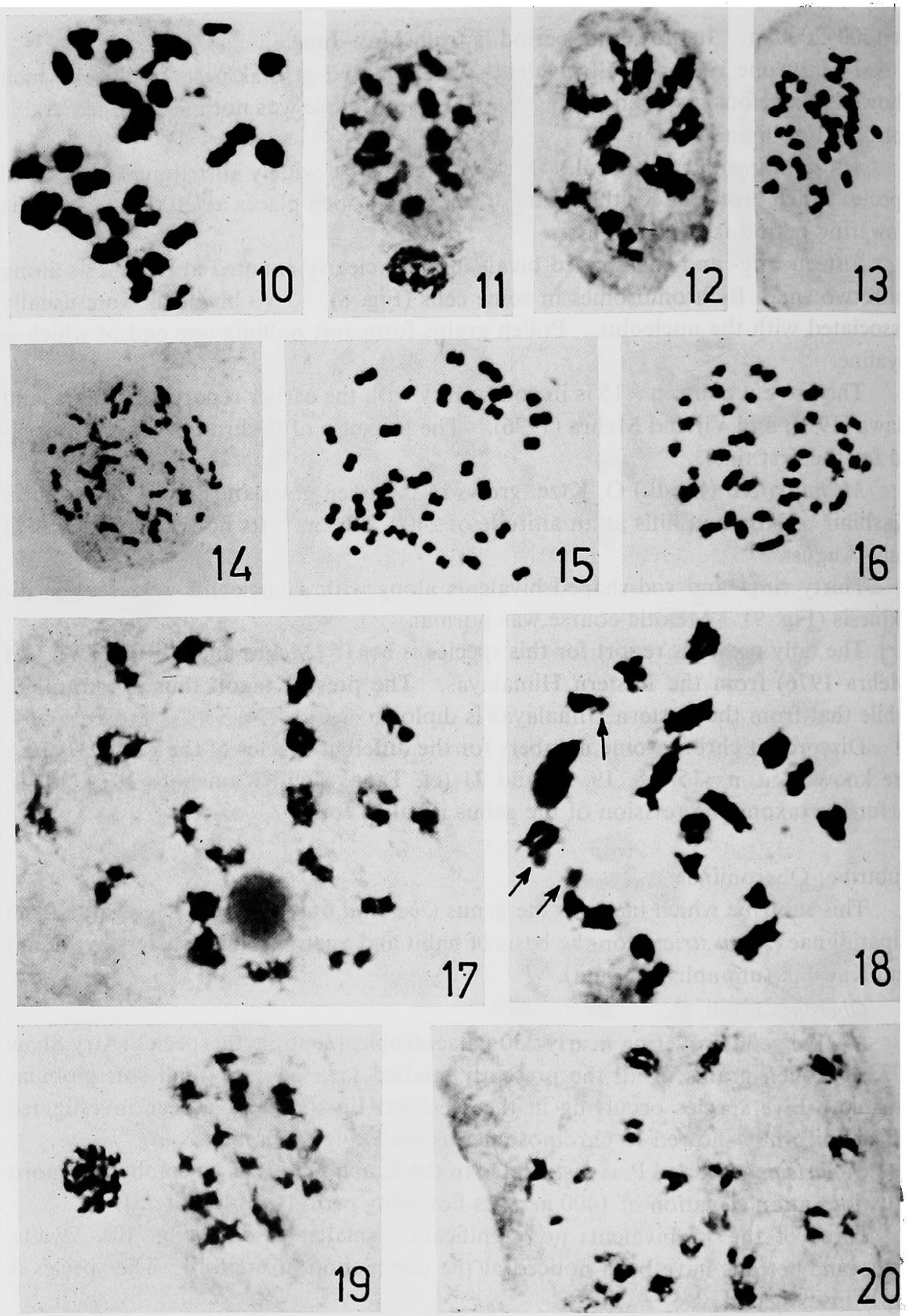

Figs. 10-20. Oberonia auriculata: 10, two PMC's with $\mathrm{n}=15$ at M-I. O. ensiformis: 11, PMC showing fifteen bivalents at diakinesis. (Two are lighthy stained). O. myriantha: 12, PMC with 15 bialents at diakinesis. $O$. pachyrachis: 13 , somatic cell with $2 \mathrm{n}=30$ chromosomes at metaphase. Bulbophyllum raui: 14 , somatic cell with $2 \mathrm{n}=40$ chromosomes. B. reptans: 15 , somatic cell with $2 n=38$ chromosomes at metaphase. $B$. umbellatum: 16 , somatic cell with $2 n=38$ chromosomes. Cirrhopetalum refractum: 17, PMC with $\mathrm{n}=19$ at diakinesis. $C$. viridiflorum: $18, \mathrm{PMC}$ with $\mathrm{n}=$ $19+3 \mathrm{~B}$ 's at diakinesis (B's at arrow). Dendrobium alpestre: 19 , PMC with $\mathrm{n}=19$ at M-II. D. aphyllum: 20, $\mathrm{PMC}$ with $\mathrm{n}=19$ at diakinesis. 
valley, ascending up to $1300 \mathrm{~m}$. Its flowering period is December.

Meiotic studies revealed 15 bivalents at diakinesis thus confirming the only earlier report of Vij et al. (1976a).

O. myriantha Lindl. also grows as an epiphyte in thick forests of Kumaon hills at an elevation of $1300 \mathrm{~m}$. Its flowering peroid is August.

Fifteen ring- and rod-shaped bivalents were observed at diakinesis (Fig, 12). This confirms the earlier reports of $2 n=30$ by Vij et al. (1976a) and $n=15$ by Mehra and Sehgal (1978).

O. pachyrachis Reichb. $\mathrm{f}$. is a very common branch epiphyte in the Kumaon hills at $1400-1600 \mathrm{~m}$. Its flowering period is October.

Somatic studies from root tip mitosis revealed $2 n=30$ (Fig. 13) and is in line with the findings of Mehra and Sehgal (1975) and Vij et al. (1976a).

Literature studies reveal that the genus consistently shows the chromosome numbers of $n=15,2 n=30$ in all the species so far investigated. A discordant number was reported $2 \mathrm{n}=\mathrm{ca} .36$ by Arora (1971) which appears erroneous. Jorapur and Hedge (1975) worked out 5 species of this genus with $2 n=30$ from the Western Ghats. The basic number $x=15$ is suggested for this genus.

Subtribe: Dendrobiinae Bentham

Dressler and Dodson (1960) placed 6 genera under this subtribe. To date only 3 genera Bulbophyllum, Cirrhopetalum and Dendrobium are to some extent known cytologically while the others are completely untouched. Many workers have made valuable contributions to the cytology of this subtribe (cf. Tanaka and Kamemoto 1972, 1974).

Presently eleven species are studied belonging to 3 genera. Pollen grains in these adhere in tetrads forming soft pollinia.

Bulbophyllum Thou.

As many as 900 species belong to this epiphytic genus which are distributed in the tropical and southern temperate regions (Airy Shaw 1973), and only 4 of which are met in the Western Himalayas (Duthie 1906).

B. raui Arora is an epiphyte in the Kumaon hills on branches of trees at $1400 \mathrm{~m}$.

Somatic studies from root tip mitosis revealed $2 n=40$ chromosomes (Fig. 14) which are rather small and unsuited for karyotypic analysis. The species is studied for the first time.

B. reptans Lindl. is an epiphytic species which grows at about $1400 \mathrm{~m}$ in the Kumaon hills.

Thirty eight chromosomes were clearly counted at metaphase from root tip mitosis (Fig. 15). These show gradual gradation in size (Fig. 29) and range from 2.11-0.79 $\mu$. Total chromosome length is $56.68 \mu$. Karyotypic formula is $34 \mathrm{~m}+$ $4 \mathrm{sm}$. Mehra and Sehgal (1975) reported $\mathrm{n}=19+0-2 \mathrm{~B}$ 's and Vij et al. (1976a) $\mathrm{n}=19$. A discordant number $2 \mathrm{n}=42$ was reported by Chatterji (1968b). $1500 \mathrm{~m}$.

B. umbellatum Lindl. also grows as an epiphyte in the Kumaon hills at about

Mitotic studies from root tips revealed $2 n=38$ (Fig. 16). The chromosomes range from 1.85 to $0.66 \mu$. Total chromosome length is $39.73 \mu$. The karyotype 
consists of $30 m+4 s m+4$ st chromosomes. Previous record of $2 n=38$ by Chatterji (1968a), Vij and Mehra (1976) and Vij et al. (1976a) under Cirrhopetalum maculosum is confirmed.

The somatic chromosome numbers $2 \mathrm{n}=38$ and $2 \mathrm{n}=40$ (see Tanaka and Kamemoto 1972, 1974) are the most common for the genus Bulbophyllum, suggesting $x=19,20$. The only other reports are $2 n=36$ (Sharma and Chatterji 1966) and $2 n=$

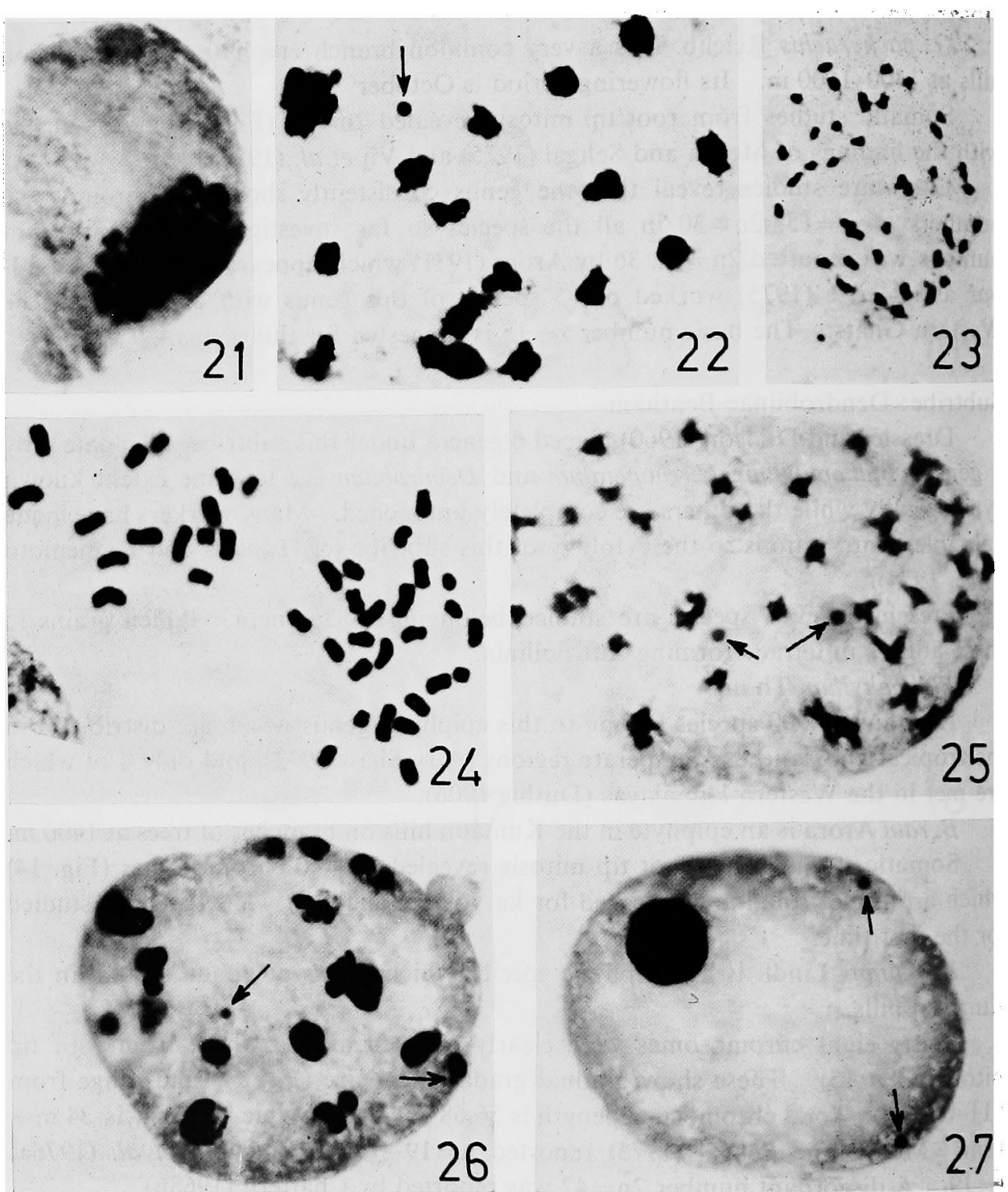

Figs. 21-27. Dendrobium aphyllum: 21, a monad. D. bicameratum: 22, PMC with $\mathrm{n}=19+2 \mathrm{~B}$ 's at diakinesis. 23 , somatic cell with $2 n=38$ chromosomes. D. chrysanthum: 24 , somatic cell with $2 \mathrm{n}=40$ chromosomes at metaphase. D. primulinum: 25 , mixed M-II with $2 \mathrm{n}=38$. Note persistent nucleoli with nucleolinus (at arrow). 26, abnormal mother cell with many micronuclei. 27, a monad, with persistent nucleolinus at arrow. 
48 (Eftimiu-Heim, 1941). Dacker (1970) has suggested $x=19$ for the genus.

Cirrhopetalum Lindl.

The genus includes 70 epiphytic species, distributed in tropical Africa, Mascrene, Indomalaya and Tahiti (Airy Shaw 1973). Only 3-4 species are met in the Western Himalayas of which 2 have been investigated.

C. refractum Zoll. grows as an epiphyte on the trunks of trees in the Kumaon hills at about $1400 \mathrm{~m}$. Its flowering period is August.

Meiotic studies revealed $n=19$ at diakinesis (Fig. 17) besides a lightly stained nucleolus. Bivalents were both ring- and rod-shaped. Meiotic course was normal. This species is investigated for the first time.

C. viridiflorum Lindl. is an addition to the orchid flora of Western Himalayas. It grows epiphytically on tree trunks at an elevation of $1500 \mathrm{~m}$. Flowering period is in August-September.

Meiotic studies revealed $n=19+1-3 B$ s at diakinesis (Fig. 18). Bivalents were both ring- and rod-shaped. One of the bivalents was found associated with the nucleolus. The present count is in line with the earlier report $\mathbf{n}=19$ by Mehra and Vij (1970). Presence of B's is noticed for the first time.

Most of the members of the genus Cirrhopetalum worked out by Chardard (1963) showed $2 n=38-40$ and $2 n=38$. Vij and Mehra (1976) too reported $n=19$, 20 for the species they investigated. The only known discordant number is $2 n=48$ (Eftimiu-Heim 1941).

Dendrobium $\mathrm{Sw}$.

It is the largest epiphytic genus with 1400 species, distributed from tropical Asia to Polynesia and Australia (Airy Shaw 1973). Due to thir showy and fascinating flowers, many species are of great ornamental value. Nearly 15 species are distributed in the Western Himalayas (Duthie 1906) of which 6 have been investigated.

$D$. alpestra Royl. grows as an epiphyte at an elevation of $1300-1600 \mathrm{~m}$ in the Kumaon hills, mostly on oaks. Its flowering period is July-August.

Meiotic studies in the PMC's revealed $n=20$ at M-II (Fig. 19). The two diad nuclei at this stage were asynchronous. Meiotic course was normal. The present count is in conformity with the earlier reports by Arora (1968) and Vij et al. (1976a).

D. aphyllum (Roxb.) C. E. C. Fischer grows as an epiphyte at an altitude of $1500-1700 \mathrm{~m}$ in the Kumaon hills. It possesses beautiful inflorescences which appear in March-April.

The chromosome number $n=19$ was observed at diakinesis (Fig. 20). Some of the bivalents showed precocious disjunction. Monads (Fig. 21) and dyads were also observed besides the normal tetrads.

The gametic chromosome number was further confirmed from root tip mitosis which revealed $2 n=38$ chromosomes. These were rather small and appeared to possess median and submedian primary constriction.

The present counts $n=19,2 n=38$ are in line with the previous report of $2 n=38$ by Jones (1963). Chardard (1963) reported $n=19,20$, and Roy and Sharma (1972) $2 n=40$. Polysomaty has been observed by Sharma and Chatterji (1966).

D. bicameratum Lindl. grows as an epiphyte in the thick forests of Kumaon hills at about $1400 \mathrm{~m}$, flowering during July-August. 
Meiotic studies revealed $n=19+0-4 B$ 's at diakinesis (Fig. 22). Bivalents were mostly ring- and rod-shaped. Root tip mitosis also revealed $2 \mathrm{n}=38$ (Fig. 23).

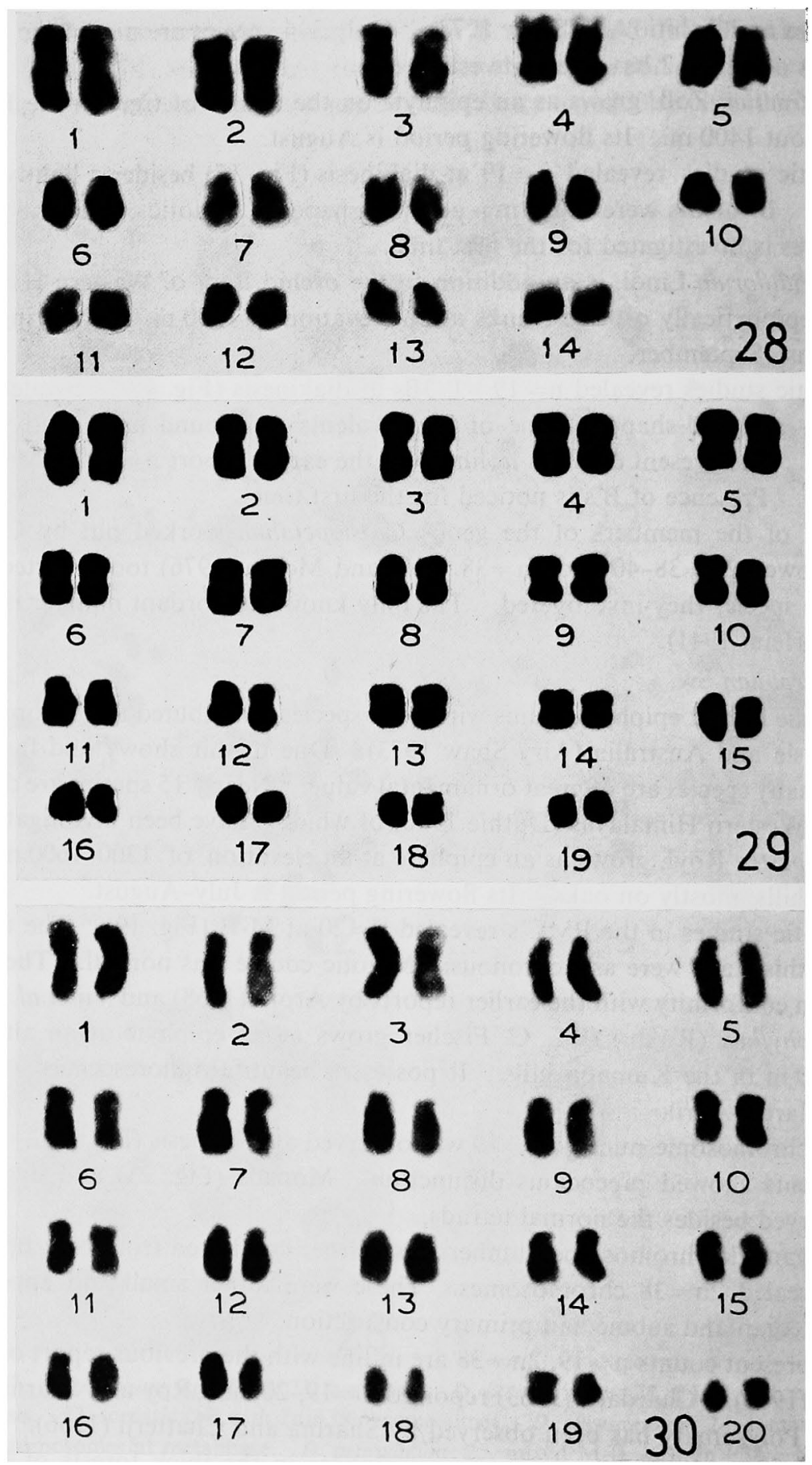

Figs. 28-30. 28, karyogram of figure 5 (Liparis rostrata). 29, karyogram of figure 15 (Bulbophyllum reptans). 30 , karyogram of figure 24 (Dendrobium chrysanthum). All $\times 4530$. 
Chromosome size was rather small for karyotypic analysis.

Aroa (1968) reported $2 n=40$ for this species, perhaps the error is due to the occurrence of B's. Vij and Mehra (1976) reported $n=19$.

D. chrysanthum Wall. is an epiphyte in the forests of Kumaon hills at about $1200 \mathrm{~m}$ elevation. The flowers appear during August-September.

Mitotic determination from young vegetative pseudobulbs showed $2 n=40$ chromosomes at metaphase (Fig. 24). They showed gradual size gradation (Fig. 30) and measured from $2.64-1.05 \mu$. Total chromosome length is $74.70 \mu$. Karyotype comprises $14 \mathrm{~m}+14 \mathrm{sm}+12$ st chromosomes.

The present somatic count of $2 n=40$ confirms the earlier report of $n=20$ by Mehra and Sehgal (1976) from the Eastern Himalayas, while the other reports are of $\mathrm{n}=19,2 \mathrm{n}=38$ (cf. Tanaka and Kamemoto 1972, 1974, Vij and Mehra 1976).

D. fimbriatum Hook. grows as an epiphyte on oaks in the Kumaon hills at an elevation of about $1400 \mathrm{~m}$. This species is of great ornamental value and possesses beautiful yellow flowers. Its flowering period is April-May.

The gametic chromosome number $n=19$ was counted at pollen mitotic metaphase. Dyads and triads were also observed besides the normal tetrads. The present count is in agreement with the previous reports (cf. Tanaka and Kamemoto 1972, 1974, Vij and Mehra 1976) except for $\mathrm{n}=20$ by Arora (1971).

D. primulinum Lindl. grows as an epiphyte in the Kumaon hills at about $1000 \mathrm{~m}$. Its flowering period is April.

Meiotic studies revealed $2 \mathrm{n}=38$ at mixed M-II (Fig. 25). An interesting feature is the persistence of nucleoli throughout the meiotic cycle. A darkly stained dot-like nucleolinus was always found embedded in the nucleoli (Fig. 25). Multinucleate aberrant PMC's were not rare (Fig. 26). Besides normal tetrads, monads (Fig. 27) and dyads were not uncommon. The percentage of abnormal pollen grains was about $30 \%$.

Somatic studies from root tips revealed $2 n=38$. Chromosome size ranges from 2.69-0.92 $\mu$ within the complement. Total chromosome length is $64.1 \mu$. Karyotype comprises $32 \mathrm{~m}+4 \mathrm{sm}+2$ st chromosomes. The present counts $\mathrm{n}=19$ and $2 n=38$ are in agreement with the previous reports (cf. Tanaka and Kamemoto 1972, 1974). Vij et al. (1976a) have reported a triploid race with $2 \mathrm{n}=57$.

A perusal of literature reveals that majority of the cytologically known species of the genus fall under $n=19$ or 20 (cf. Tanaka and Kamemoto 1972, 1974). Of these two numbers, $n=19$ is the more common.

Darlington and Wylie (1955) suggested two basic numbers $x=10$ and 19 for Dendrobium. Jones (1963) considered the genus to be dibasic with $\mathrm{x}=19$ and 20 . He further stated that the taxa with $2 n=40$ can be balanced aneuploids with $2 x+2$ constitution.

Hybridization is common in Dendrobium. Most of the hybrids exhibit variable chromosome numbers (cf. Dorn and Kamemoto 1962, Kosaki and Kamemoto 1961, Vajrabhaya and Randolph 1961, Jones 1963, etc.). Kosaki and Kanemoto (1961) and Jones (1963) also reported variable numbers in some of the natural species. The latter author found maximum range of variation $2 n=38-114$ in $D$. kingiaum. He also makes a specific mention of heterogenous chromosome size 
in the genus. Presently large-sized chromosomes were observed in $D$. chrysanthum (Fig. 24) and small dot like in D. bicameratum (Fig. 23). Triploids and some higher polyploids are recorded in some species/hybrids of Dendrobium (cf. Tanaka and Kamemoto 1972, 1974).

All the presently studied 12 species of subtribe Dendrobiinae are built mostly on $\mathrm{x}=19$ or 20 . Chromosome size also varies within the subtribe. In Bulbophyllum raui chromosomes are very small while in Dendrobium chrysanthum they are fairly large.

\section{Summary}

Cytological studies were carried out in 24 species belonging to 6 genera of Liparidinae, Oberoniinae and Dendrobiinae. Five species, Liparis cordifolia $(\mathrm{n}=$ $10)$, L. deflexa $(\mathrm{n}=21)$, Oberonia auriculata $(\mathrm{n}=15)$, Bulbophyllum raui $(2 \mathrm{n}=40)$ and Cirrhopetalum refractum $(\mathrm{n}=19)$ are investigated for the first time. New chromosome numbers were added to five species. The genus Oberonia shows a consistent basic chromosome number of $n=15$.

\section{Literature cited}

Airy Shaw, H. K. 1973. A Dictionary of the Flowering Plants and Ferns (Revised 8th ed. of the late J. C. Willis). University Press, Cambridge.

Arora, C. M. 1968. In IOPB chromosome number reports XVI. Taxon 17: 199-204.

- 1971. In IOPB chromosome number reports XXXIV. Taxon 20: 785-797.

Chardard, R. 1963. Contribution à l'étude cytotaxonomique des Orchidées. Rev. Cyt. et Biol. Veg. 26: 1-58.

Chatterji, A. K. 1968a. Chormosome numbers and karyotypes of some orchids. Amer. Orchid Sco. Bull. 37: 202-205.

- 1968b. Orchid cytology in India. Jour of Cytol. and Genet. 3: 32-40.

Daker, M. G. 1970. The chromosomes of orchids, IV. Bulbophyllinae Schltr. Kew Bull. 24: 179184.

Darlington, C. D. and Wylie, A. P. 1955. Chromosome Atlas of Flowering Plants. George Allen and Uuwin Lid. London.

Dorn, E. C. and Kamemoto, H. H. 1962. Chromosome transmission of Dendrobium phalaenopsis (Lyons Light No. 1). Amer. Orchid Soc. Bull. 31 : (12) 997-1006.

Dressler, R. L. 1974. Classification of the orchid family. Proc. of the 7 th World Orchid Conf. 259-279.

- and Dodson, C. H. 1960. Classification and phylogeny in Orchidaceae. Ann. Missouri Bot. Gard. 47: 25-68.

Duthie, J. F. 1906. The orchids of North-Western Himalayas. Ann. Roy. Bot. Gard. Calcutta 9: 81-211.

Eftimiu-Heim, P. 1941. Recherches sur les noyaux des Orchidées. Le Botaniste 31: 65-111.

Ito, I. and Mutsuura, O. 1957. Chromosome numbers in Dendrobium species and hybrids. Japan Orchid Soc. Bull. 3 (1): 1-3.

Jones, K. 1963. The chromosomes of Dendrobium. Amer. Orchid Soc. Bull. 32 (8): 634-640.

Jorapur, S. M. and Hedge, S. N. 1975. Karyomorphological studies in the five species of Oberonia Lindl. Cytologia 40: 517-524.

Kamemoto, H. H. and Sagarik, R. 1967. Chromosome numbers of Dendrobium species of Thailand. Amer. Orchid Soc. Bull. 36(10): 889-894. 
Kosaki, K. and Kamemoto, H. H. 1961. Chromosomes of some Dendrobium species and hybrids. Na Pua Okika O Hawaii Nei 11 (7): 75-86.

Mehra, P. N. and Bawa, K. S. 1962. Chromosome studies in Orchidaceae. Proc. Ind. Sci, Congr. 326-327.

- and - 1970. Cytological observations of North-West Himalayan orchids. Caryologia 23: 273-282.

- and Kashyap, S. K. 1983. Cytological Investigations on West-Himalayan orchids. Tribe: Orchideae I. The genus Habenaria Willd. Cytologia 48: 633-646.

- and Pal. Y.1961. The cytological observations on some Indian members of Orchidaceae. Proc. Ind. Sci. Congr. p. 294.

- and Sehgal, R. N. 1975. In IOPB chromosome number reports XLIX. Taxon 24: 501-506.

- and - 1976. In IOPB chromosome number reports LIV. Taxon 25: 631-649.

- and - 1978. In IOPB chromosome number reports LXI. Taxon 27: 375-392.

- and Vij, S. P. 1970. In IOPB chromosome number reports. Taxon 19: 102-113.

Roy, S. C. and Sharma, A. K. 1972. Cytological studies of Indian orchids. Porc. Indian Nat. Sci. Acad. Vol. 38, Part B, Nos. 182: 72-86.

Seidenfaden, G. 1975. Contributions to a Revision of the Orchid Flora of Cambodia, Laos and Vietnam I. A preliminary enumeraiion of all orchids hitherto recorded. Fredensborg, Denmark.

Sharma, A. K. and Chatterji, A. K. 1966. Cytological studies on orchids with respect to their evolution and affinities. The Nucleus 9: 177-203.

Tanaka, R. and Kamemoto, H. H. 1972. A complete tabulation of chromosome numbers in Orchidaceae. Reprinted from the Orchids, Culture and Breeding. Edited by SeibundoShinkosha Co. Ltd., Tokyo (pp. 800): 667-773.

- and - 1974. List of chromosome numbers in species of Orchidaceae. pp. 411-483 (vide C. L. Withner, 1974).

Vajrabhaya, T. and Randolph, L. F. 1961. Chromosome inheritance in pentaploid and aneuploid Cattleyas. Amer. Orchid Soc. Bull. $30: 209-213$.

Vij, S. P. and Mehra, P. N. 1976. Cytological studies in the East Himalayan Orchidaceae IV. Epidendreae. Epidendreae. Research Bull. (Sci.) of the Panjab Univ. 27 (1 and 2): 5198.

-, Gupta, G. C. and Garg, A. K. 1976. In IOPB chromosome number reports LIV. Taxon 25: 631-649.

-, Arora, A. and Nanda, U.S. 1976. In IOPB chromosome number reports LIV. Taxon 25: 631-649.

Withner, C. L. 1974. The Orchids: Scientific Studies. A Wiley Interscience Publication. 